\title{
On the Effective Connection between Advanced Mathematics and Middle School Mathematics in Teaching Content and Method
}

\author{
Nie Raorong, Zhu Huaihong \\ Nanchang Institute of Science and Technology, Nanchang, China
}

Keywords: advanced mathematics; middle school mathematics; teaching model; teaching content; connection

\begin{abstract}
Mathematics, as an important curriculum in China's education, has significance on developing students' logical thinking ability and problem-solving ability, and can be effectively applied to their future work and life. For college students, advanced mathematics not only can help them better understand major courses, also can allow them to have better learning experience in mathematics learning, give full play to their potential and cultivate the ability of various aspects. However, there is certain difference in the learning of middle school mathematics and advanced mathematics, in teaching content and teaching method, thus it is important to realize the effective connection between advanced and middle school mathematics in teaching content and method. This paper is based on the current status of teaching content reform of middle school mathematics in new curriculum standard, analyzes the effective connection between the both in three aspects, and finally discusses how to effectively connect the both.
\end{abstract}

\section{Introduction}

Mathematics plays a significant role in middle school teaching and college teaching. However, there are some problems in the students' learning of advanced mathematics. There is no relation between the teaching content of advanced mathematics and middle school mathematics course, and teaching methods are different, which directly leads to the higher difficulty in students' learning of advanced mathematics, thus mathematics knowledge learned before cannot be effectively applied to the learning of advanced mathematics. At the same time, changes of teaching method also directly drives students to change leaning way, which reduces teaching efficiency of advanced mathematics to certain extent, and impacts on students' actual leaning achievements.

\section{The Current Status of Teaching Content Reform of Middle School Mathematics in New Curriculum Standard}

With the continuous development of China's middle school teaching system, in order to better implement quality-oriented education and realize teaching objectives, teaching reform of new curriculum standard has been implemented in current middle school mathematics. Therefore, there are bigger changes in teaching content of middle school mathematics, especially adding some content of advanced mathematics, even some content not related to advanced mathematics, such as Euler's formula, geometry of the sphere and so on, also correspondingly eliminating some relevant content, such as inverse trigonometric functions. Whereas, it is notable that although there is not related requirements in the learning and grasping of inverse trigonometric functions in middle school mathematics teaching, there is certain requirements in advanced mathematics. For instance, for polar coordinates is alternative in middle school mathematics, however, there is not the teaching of polar coordinates in advanced mathematics, but the direct application to definite integral in advanced mathematics, which greatly increases the difficulty of advanced mathematics learning to certain extent. As for teaching reform in middle school mathematics, the content of mathematics is reduced more in liberal arts, such as permutations and combinations, mathematical induction and so on, which causes the discontinuity between advanced mathematics and middle school mathematics, and obstacles in the teaching process of advanced mathematics. 
In the process of learning mathematics, guiding students to understand and master the correct rules of thinking and inference proof, can ensure that students learn the basics of mathematics in the process of learning mathematics, and ultimately improve the basic ability of mathematics. In the teaching of middle school mathematics, mathematical concepts and thinking methods are also briefly introduced, which are often scattered and not specific, and important learning methods are not specifically introduced, which directly leads to the fact that in the later studies of advanced mathematics, many students will feel that the learning of advanced mathematics is very boring, and the difficulty of learning advanced mathematics will be greatly increased.

\section{The Effective Connection between Advanced Mathematics and Middle School Mathematics in Teaching Method}

There is a certain difference in advanced mathematics and middle school mathematics in teaching methods, therefore, it is necessary to take corresponding measures to realize the effective connection between advanced mathematics and middle school mathematics in teaching method. This paper analyzes three aspects. First of all, to focus on the charm and significance of first class; secondly, focus on the teaching of basic concept, basic theory and basic method; thirdly, focus on the effective connection between advanced mathematics and middle school mathematics in teaching method.

\subsection{To focus on the charm and significance of first class}

In the learning of advanced mathematics, many students feel boring, so it is necessary to change this idea by the first mathematics class. Before the class, the teacher is required to design the course, present main content and characteristics, and elaborate the importance of learning mathematics to students, and difficulties in various aspects that may occur in the learning of advanced mathematics, so as to inspire their interests to learn mathematics more actively, which can effectively lay a solid foundation for the improvement in the efficiency of mathematics class.

What kind of content shall be included in the first class? It is believed in this paper that the relation and difference between advanced mathematics and middle school mathematics shall be described first, then the importance, learning method and various problems of learning advanced mathematics shall also be presented in detail.

First of all, it is necessary to make the relation and difference between advanced mathematics and middle school mathematics clear. Limit, the core and basis of advanced mathematics, integrated through it, is a dynamic process with functions as research object. However, the learning content and processing method of the unlimitedness and dynamic nature of limit is fundamentally different from middle school mathematics. Whereas, there is also close relation between the both. Advanced mathematics is to improve the capability of analyzing and solving problems, thus it pays more attention to the width and depth, however, middle school mathematics more focuses on grasping basic knowledge for exams. Besides, the strict logicality, abstraction of limit and the wide applicability of advanced mathematics shall also be emphasized.

Secondly, the importance, learning method and various problems of learning advanced mathematics shall also be presented in detail, which is mainly to guide students to have a clearer understanding of the learning of advanced mathematics, have confidence in the learning, and more actively involved in the learning of advanced mathematics. In the process of learning advanced mathematics, students' self-study of related course content is an important way and method to learn advanced mathematics. Before the course, students take the initiative to prepare relevant knowledge after class, record the key points and difficulties, and then solve them one by one in class, so that the learning can be more solid. Then students are guided to develop the habit of taking notes. The main purpose of taking notes is to guide students to think and analyze problems independently, and also enable students to play an important role in the future review. Then students are encouraged to ask questions from teachers, which will help students solve problems in a timely manner, so that the knowledge points learned in the classroom can be effectively consolidated and improved. Finally, students are guided to comprehensively review the textbook, and to make a simple review outline to 
cultivate students' knowledge integration ability and also cultivate students' better learning habits.

\subsection{To focus on the teaching of basic concept, basic theory and basic method}

When learning advanced mathematics, most students think the main purpose of learning mathematics is to solve relevant mathematics problems, ignoring the importance of understanding basic mathematics knowledge, which causes the unclear thinking and inappropriate method in learning advanced mathematics. Therefore, in learning advanced mathematics, teachers are require to help students transform the thinking, and realize the importance of basic concept, basic theory and basic method of advanced mathematics. However, it shall be noted that students may cannot understand excessively abstract content, thus teachers are required to take corresponding measures to help them understand, such as materializing and visualizing abstract content by metaphor.

\subsection{To focus on the effective connection between advanced mathematics and middle school mathematics in teaching method}

In the teaching of advanced mathematics, the previous chapters are the basis of the entire advanced mathematics curriculum, so it is necessary to help students learn the knowledge of this part. Then, in teaching, teachers can consciously link teaching method of this part with middle school mathematics teaching method, that is, to teach the difficult points in advanced mathematics, and have a clear blackboard-writing, which will give students a very rigorous example. In addition, a variety of methods to prove the theorem can be provided, which helps students to have divergent thinking. Finally, at the end of the course, some relevant questions can also be set for students to think after class, which can effectively help students to quickly follow the methods and characteristics of advanced mathematics teaching in colleges and universities, and it is of great help and significance for students to learn advanced mathematics in the future.

\section{The Effective Connection between Advanced Mathematics and Middle School Mathematics in Teaching Content}

In the last section, the effective connection between advanced mathematics and middle school mathematics in teaching content is analyzed in detail. Compared with the content of middle school mathematics, advanced mathematics is the expansion of mathematics knowledge in width and depth. To realize the connection, it is necessary for students to know the strict logicality, abstraction and the wide applicability of advanced mathematics. In this paper, according to basic teaching material of advanced mathematics, it is necessary to optimize the content of teaching material.

In this paper, the content to be optimized include three aspects. First of all, to eliminate all content of middle school mathematics; secondly, to analyze and present mathematics concept and thinking method to be grasped by students; thirdly, to take frequently-used equation, polar coordinates equation, curves and so on as appendix to help students to learn advanced mathematics.

There are also different ways of learning different mathematics content. Generally speaking, there are three main ways to learn advanced mathematics content. First, students' independent learning; second, lecture materials produced by teachers uploaded online for students' independent learning; thirdly, key points and difficulties of advanced mathematics knowledge taught by teachers, and other knowledge learned by students themselves.

This paper presents reasons for these content. First of all, in the learning of advanced mathematics, the connection and difference between the polar coordinate system and the rectangular coordinate system can be seen clearly. For example, it is more simple and convenient for many curves to be expressed in polar coordinate system, but definite integral and double integral are more suitable for rectangular coordinate system. However, in middle school mathematics, there is no introduction about the content of the polar coordinate system. At this time, students can learn the polar coordinate system only in advanced mathematics curriculum, so that they can better apply this tool and better learn advanced mathematics. Secondly, in the teaching of limit in advanced mathematics, the analysis method is mainly used, but there is no specific learning on the analysis method in middle school mathematics. Then, during the practice of exercises, many techniques are 
not able to fully cope with the solutions to the advanced mathematics questions. Instead, it is necessary to apply equations and methods in middle school mathematics to solve the relevant problems effectively. Finally, in the learning of advanced mathematics, it is also very necessary to master the frequently-used equations and methods of middle school and advanced mathematics, so as to effectively improve the efficiency and speed of learning.

\section{Conclusion}

In short, the reform of the content of middle school mathematics curriculum will directly affect the teaching of advanced mathematics content. Only through the reform of middle school mathematics content, teachers can adopt corresponding countermeasures in the teaching of advanced mathematics to carry out more effective teaching. In particular, the reform of the content of middle school mathematics courses will directly lead to the deviation of the teaching of advanced mathematics content from middle school mathematics content, which will directly lead to various problems students experience in the process of advanced mathematics learning, for example there is no a certain knowledge point that needs to be mastered in advanced mathematics in advanced mathematics teaching content, and in middle school mathematics teaching content, which reduces the learning speed of students. This paper mainly describes the current status of content reform of middle school mathematics in new curriculum standard, and the effective connection between advanced mathematics and middle school mathematics in teaching content and teaching method, discusses focusing on the charm and importance of first class, focusing on the teaching of basic concept, basic theory and basic method, and focusing on the effective connection between advanced mathematics and middle school mathematics in teaching method, and analyzes the effective connection between advanced mathematics and middle school mathematics in teaching content. This paper can provide certain reference for relevant personnel.

\section{References}

[1] Tang Shengda. Discussion on the Teaching Reform of Higher Mathematics Based on the Passing Rate of Postgraduate Entrance Examination [J]. The Science Education Article Collects, 2018(05).

[2] Kong Shanshan. Case Teaching of Higher Mathematics in Economics [J]. Journal of Science of Teachers' College and University, 2017(2).

[3] Yan Junzhe. On the Learning of Trigonometric Function in High School [J]. SHUXUE DASHIJIE, 2017(10).

[4] Kong Shanshan. The Connection between Advanced Mathematics and Middle School Mathematics [J]. Science \& Technology Industry Parks, 2017(18).

[5] Lu Jianfang, Ding Xiaodong. Research of Teaching Mode of Higher Mathematics Specific to Postgraduate Entrance Examination: Case Study of Zhejiang University of Technology [J]. Journal of Zhejiang Institute of Science and Technology (Social Science Edition), 2017(04).

[6] You Hui, Zhu Wenfang. A Research Review on Higher Mathematics Teaching Status in China [J]. Higher Education of Sciences, 2017(03).

[7] Yang Bodi, Zhao Tianxu. Research on Connection and Measures of Higher Mathematics and Middle School Mathematics [J]. Journal of Inner Mongolia Normal University (Education Science Edition), 2017(05).

[8] Hou Jiangxia. Thinking on Improving the Quality of Classroom Teaching of Advanced Mathematics for Liberal Arts and Social Science [J]. Education and Teaching Forum, 2017(18).

[9] Sun Lina. Reflection of Teaching-Optimize Maths Teaching [J]. Journal of Nanchang College of Education, 2017(02).

[10] Wang Jian. On the Teaching of Advanced Mathematics [J]. Journal of Jiangsu University of Technology, 2017(02).

[11] Wen Zhonglin, Yao Wenxiao. Evaluation on Logic Basis of Middle School Mathematics [J]. 
Journal of Yunnan University of Education, 1995(02). 